JURNAL ILMU LINGKUNGAN

Volume 11 Issue 2: 92-99 (2013) ISSN 1829-8907

\title{
IDENTIFIKASI KEMISKINAN AIR DI DAERAH ALIRAN SUNGAI CITARUM HULU: KASUS DAERAH BANDUNG RAYA
}

\author{
Nova Maulani (1), Sunardi (1,2), Dadan Sumiarsa(1.3), Djuwansah(1,4) \\ (1) Program Studi Magister Ilmu Lingkungan - Universitas Padjadjaran Bandung \\ Email : nova.maulani@gmail.com \\ (2)Program Studi Magister Ilmu Lingkungan - Universitas Padjadjaran Bandung \\ (3)Program Studi Magister Ilmu Lingkungan - Universitas Padjadjaran Bandung \\ (4)Pusat Penelitian Geoteknologi - LIPI
}

\begin{abstract}
ABSTRAK
Sungai Citarum termasuk salah satu sungai besar dan strategis di Indonesia kondisinya dalam keadaan sangat kritis. Berbagai aktivitas dengan kurang terkendalinya limbah yang dibuang ke sungai menyebabkan Sungai Citarum menghadapi berbagai permasalahan yang berdampak pada suplai air baku/bersih bagi penduduk sekitar DAS. Kritisnya tersebut sudah terjadi sejak dari bagian hulu. Sementara itu, pertumbuhan penduduk mendorong meningkatnya kebutuhan air baku untuk keperluan air domestik, pertanian, dan industri. Kondisi ini memicu terjadinya persaingan penggunaan sumberdaya air yang kemudian dapat berdampak pada terjadinya kemiskinan air di DAS Citarum Hulu. Penelitian ini dilakukan untuk mengidentifikasi kemiskinan air yang terjadi di beberapa wilayah Sungai CitarumHulu (Kabupaten Bandung, Kota Bandung, dan Kota Cimahi). Penelitian dilakukan dengan menggunakan analisis Indeks Kemiskinan Air (Water Poverty Index, WPI) dengan pendekatan komposit. Berdasarkan WPI, ketiga wilayah kajian di Citarum Hulu yakni Kabupaten Bandung, Kota Bandung, dan Kota Cimahi berada dalam kondisi kemiskinan air agak tinggi dengan masing-masing nilai WPI 38,79; 42,69; dan 38,13 (skala 100). Artinya, ketiga wilayah tersebut masuk dalam kategori tidak aman.
\end{abstract}

Kata Kunci: Citarum Hulu, Kemiskinan Air, Indeks Kemiskinan Air, Pengelolaan Sumber Daya Air

\section{ABSTRACT}

Citarum watershed is one of the major rivers and has a strategic role in Indonesia. Nowadays, it is in criticial condition. Various activities with huge wastes dumped in the river lead Citarum facing many problems that impact on the supply of clean water for population. Those problems have occured in upstream area. Meanwhile, population pressure urges the increase of water needs specifically for domestic, agriculture, and industry purposes. This condition triggers competition of water uses which can impacts on water poverty in the UpperCitarum. The aim of this study is to identify water poverty of the UpperCitarum Water shed (Bandung, Kota Bandung, and Kota Cimahi Area). The study is conducted using Water Poverty Index (WPI) analysis with composite approach. Based on WPI, the water poverty in each area of study is medium high with value for Bandung 38,79; Bandung City 42,69; and Cimahi 38,13. In other words, they are under unsafe condition. Water resources management such as conservation is needd for water poverty mitigation

Keywords: Upstream Citarum Watershed, Water Poverty, Water Poverty Index, Water Resources Management 


\section{PENDAHULUAN}

Air diperlukan untuk pembangunan berkelanjutan suatu wilayah (Setiawan, 2009). Distribusi akses air yang cukup adalah cerminan distribusi kesejahteraan (United Nations Development Programme, 2006). Kebutuhan akan air terus meningkat seiring dengan bertambahnya jumlah populasi manusia (Oki and Kanae, 2006). Berbagai kegiatan dan proses yang dilakukan manusia, baik dari segi demografi, ekonomi, maupun sosial, mengarahkan tekanan pada sumberdaya air (World Water Assessment Programme, 2009).

Tekanan pada sumber daya air kemudian menyebabkan jutaan populasi manusia kesulitan dalam memperoleh air bersih untuk kelangsungan hidupnya (Bushnaq, 2004). Kondisi ketika sumberdaya air membatasi atau memiliki dampak pada kelangsungan hidup manusia digambarkan dengan istilah kemiskinan air (Kemp-Benedictet al., 2010). Forum Global Air mendefinisikan kemiskinan air sebagai keadaan seorang individu, rumah tangga, atau masyarakat tidak memiliki akses air yang cukup dengan kuantitas yang dapat diterima untuk memenuhi kebutuhan dasar (Chan, 2012).

Di Jawa Barat, pemenuhan kebutuhan air penduduk disuplai sebagian besar dari Sungai Citarum dan air bawah tanah. Seiring dengan pertumbuhan sosial dan ekonomi di Indonesia, Sungai Citarum sebagai sumber utama suplai air penduduk Provinsi Jawa Barat mengalami kondisi kritis. Selain itu, tekanan penduduk dan aktivitasnya yang terus meningkat menyebabkan perubahan penggunaan lahan, kondisi ini akan menimbulkan fenomena banjir dan kekeringan (Wangsaatmaja dkk., 2006). Di sisi lain, kebutuhan air baku terus meningkat untuk keperluan air domestik, pertanian, dan industri. Kondisi ini memicu terjadinya persaingan penggunaan sumberdaya air yang kemudian dapat berdampak pada terjadinya kemiskinan air di DAS Citarum. Isu kritis air yang terjadi di DAS Citarum dapat mengancam kelangsungan hidup masyarakat yang tinggal di wilayah tersebut dan menghambat proses pembangunan.

Suatu analisis interdisiplin diperlukan dalam pengelolaan sumberdaya air yang mengalami tekanan seperti kemiskinan air yakni dengan menggunakan Indeks Kemiskinan Air (WPI). Indeks yang dikembangkan oleh Lembaga Ekologi Wallingford (Sullivan, 2002) ini bertujuan untuk menanggulangi masalah dalam sumberdaya air dengan tujuan melakukan perkiraan ketersediaan air secara fisik yang dikaitkan dengan variabel sosio-ekonomi yang mencerminkan kemiskinan. Dengan pendekatan ini kondisi sumberdaya air dapat dikontrol sehingga ketersediaannya dapat memenuhi kebutuhan populasi manusia baik pada saat ini maupun masa depan.

\section{Pengenalan}

(identifikasi) permasalahan kondisi daerah kajian, yakni DAS Citarum Hulu, dilakukan dengan menganalisis tingkat kemiskinan air di wilayah-wilayah tersebut. Karena strategi yang lebih bijak, maka pengelolaannya berkelanjutan. ujuan penelitian ini adalah mengidentifikasi kemiskinan air yang terjadi di beberapa wilayah pada Sungai CitarumHulu.

\section{LOKASI PENELITIAN}

DAS Citarum Hulu secara geografis terletak pada 107015' BT 107060' BT dan 6040' LS - 7015' LS dan secarageomorfologi adalah Cekungan Bandung yang meliputi wilayah dengan luas sekitar 181.027 hektar (Haryanto dkk., 2007; Indriatmoko, 2004).

Dalam RT RW Metropolitan Bandung Area tahun 2005, disebutkan bahwa kawasan Bandung Raya terdiri atas 5 wilayah, yaitu: Kabupaten Bandung, Bandung Barat, Sumedang (yang berbatasan dengan Kota Bandung dan Kabupaten Bandung), Kota Bandung, dan Cimahi dengan Kota Bandung sebagai pusatnya (PSDA, 2010; Dirjen Cipta Karya, 2011). Dalam penelitian ini, analisis kemiskinan air di DAS Citarum 
Hulu menggunakan pendekatan wilayah administratif. Kajian difokuskan pada tiga wilayah administratif yakni Kabupaten Bandung, Kota Bandung, dan Kota Cimahi.

\section{METODOLOGI}

Identifikasi Kemiskinan Air dilakukan dengan menggunakan metode perhitungan komposit nilai Indeks Kemiskinan Air (WPI) yang dikembangkan oleh Pusat Ekologi dan Hidrologi Wallingford, UK (Sullivan et al., 2003). Struktur matematis penghitungan WPI digambarkan dengan persamaan berikut :

$$
\begin{gathered}
\text { Indeks Kemiskinan Air }(\quad) \\
=\frac{\sum}{\sum}
\end{gathered}
$$

Keterangan:

$$
\begin{array}{ll}
\mathrm{WPI}= & \text { indeks kemiskinan air } \\
\mathrm{Xi} & =\text { komponen (Resources, Access, } \\
& \text { Capacity, Use, Environment) } \\
\mathrm{Wi} & =\text { factor bobot masing-masing } \\
& \text { komponen }
\end{array}
$$

Persamaan di atas dijabarkan lebih lanjut dengan memasukkan setiap komponen sehingga dapat ditulis sebagai berikut :

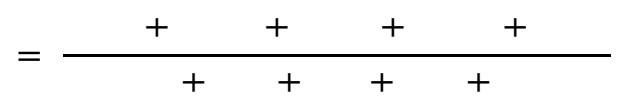

Dengan adalah factor bobot untuk masing-masing komponen Resources (Sumberdaya air), Access (Akses), Capacity (Kapasitas), Use (Pemanfaatan), dan Environment (Lingkungan) dengan jumlah sama dengan 1. Dari perhitungan tersebut, diperoleh nilai akhir yang berkisar antara 0 hingga 100, dengan nilai tertinggi menunjukkan status sumberdaya air berada pada kondisi yang paling baik (Sullivan et al., 2003). Faktor bobot dalam perhitungan ini menggunakan balance methodology yakni pemberian bobot secara sama rata (equal weights) dengan jumlah bobot sama dengan satu $(\mathrm{w}=1)$ untuk semua indikator.
Setiap komponen dihitung terlebih dahulu sebelum digabungkan dalam persamaan WPI. Lima komponen pembentuk nilai WPI terdiri atas beberapa sub-komponen yang datanya memiliki dimensi satuan berbeda sehingga dilakukan standarisasi data (Xinet al., 2011; Van der Vyer and Jordaan, 2011; Shakya, 2012). Standarisasi dilakukan dengan menggunakan metode MinimumMaksimum seperti pada formulasi berikut (Fenwick, 2010; Xinet al., 2011):

1. Berlaku untuk setiap nilai yang lebih besar dapat memberikan nilai indeks lebih besar, seperti tutupan vegetasi.

$$
=\frac{-}{\max -\min }
$$

2. Berlaku untuk nilai yang lebih kecil dapat memberikan nilai indeks lebih besar (hubungan negatif), seperti pemanfaatan air untuk industri.

$$
=\frac{\max -}{\max -\min }
$$

a. Perhitungan Komponen

Untuk setiap komponen, masing-masing variable dari subkomponen digabungkan kemudian dirata-ratakan sehingga menjadi satu nilai tunggal komponen. KomponenWPI sebagai berikut:

1) Komponen Sumberdaya air (Resources) menggambarkan kondisi banyaknya air yang tersedia (kuantitas) dengan memperhitungkan reliabilitas atau variabilitas musiman dan tahunan serta kualitas air (Xin, 2011; Sullivan and Meigh, 2006). Kuantitas air adalah ketersediaan fisik sumber daya air pada suatu lokasi (Manadhar et al., 2011). Ketersediaan air secara fisik terdiri atas air permukaan dan air bawah tanah. Ketersediaan air dapat bermakna berbeda pada tiaptiap orang. Pada penelitian ini, ketersediaan air dihitung dengan menggunakan 
pendekatan per kapita

ketersediaan air tahunan.

Data air permukaan dan air tanah diperoleh dari simulasi Basis Data Spasial Faktor-Faktor Sumber Daya Air pada Hulu DAS Citarum yang dikembangkan oleh Pusat Penelitian Geoteknologi, LIPI. Simulasi ini menggunakan aplikasi Sistem Informasi Geografi untuk menduga kuantitas komponen Sumber Daya Air bulanan secara spasial dengan metode Curve Number, Tegangan Air Tanah, dan Konduktivitas Hidraulik. Simulasi tersebut divalidasi dengan membandingkan perhitungan aktual pada hidrograf yang terekam di Stasiun Nanjung (Djuwansah dan Narulita, 2011). Ketersediaan air ditambah pula dengan kapasitas air perpipaan dalam hal ini adalah air produksi dari PAM/ PDAM (Ali, 2010).

2) Komponen Akses (Access) menggambarkan akses masyarakat untuk memperoleh air dan sanitasi. Masing-masing variable dihitung dengan persentase rumah tangga terhadap akses air bersih, sanitasi sehat, dan air limbah sehat (Zhang et al., 2012; Pandey et al., 2012; Manandhar et al., 2011) dengan data bersumber dari Departemen Kesehatan.

3) Komponen Kapasitas (Capacity) menggambarkan keefektifan dari kemampuan manusia untuk mengelola air (Mlote et al., 2002). Pada penelitian ini kapasitas terdiri atas empat variabel yang menunjukkan tingkat kesejahteraan, tingkat pendidikan, tingkat kesehatan, dan distribusi pendapatan daerah dengan data bersumber dari Badan Pusat Statistika (BPS) Jabar dan Bappeda Jabar.
4) Komponen Pemanfaatan (Use) menggambarkan kondisi air yang digunakan untuk tujuan berbeda dan kontribusinya terhadap kegiatan ekonomi karena pemanfaatan air adalah suatu prasyarat penting dalam aktivitas manusia (Sullivan, 2001 dalam Manandhar et al., 2012). Dalam penelitian Pemanfaatan terdiri atas tiga penggunaan air yang berbeda di antaranya pemanfaatan air domestik, industri, dan pertanian. Ketiga sektor tersebut dimasukkan dalam perhitungan komponen berdasarkan penggolongan pemanfaatan air oleh Gleick (1998 dalam Arsyad dan Rustiadi, 2008). Data untuk pemanfaatan air diperoleh dari DinasPemukiman\& Tata Ruang,BPS, Dinas Pertanian, ESDM, dan Dinas PSDA Jabar.

5) Komponen Lingkungan (E) berupaya mengevaluasi tingkat pemeliharaan integritas ekologi jangka panjang yang berhubungan dengan sumber daya air dan memastikan pembangunan berkelanjutan secara ekologis (Sullivan and Meigh, 2006). Dalam penelitian ini digunakan dua variabel komponen Lingkungan yaitu kualitas air dan tutupan vegetasi. Kualitas air diperoleh dari data status mutu air Sungai Citarum di beberapa pos hulu ke hilirdengan metode STORET dengan sumber data dari PSDA Jabar. Pertimbangan sulitnya memperoleh data kualitas air tanah maka dalam penelitian ini kualitas air terbatas pada air permukaan. Tutupan vegetasi adalah persentase luas hutan terhadap luas area. Hutan yang dimaksud mencakup hutan negara dan hutan rakyat. Data untuk komponen Lingkungan bersumber dari Dinas PSDA dan Dinas Kehutanan Jabar 
a. PenggabunganKomponen

Nilai WPI gabungan diperoleh dengan menjumlahkan nilai seluruh komponen yang sebelumnya telah dikalikan faktor bobot kemudian dihitung dengan pembagian sebanyak jumlah bobot, yakni satu ( $\mathrm{w}=1)$. Indeks yang telah dihasilkan kemudian distandarisasikan ke dalam skala tolak ukur (benchmark) dengan tingkat kemiskinan air (Shakya, 2012) dan standardisasi nilai keamanan sumber daya airnya berdasarkan standar yang dikembangkan oleh Pusat Ekologi dan Hirologi (CEH) Wallingford seperti pada Tabel 1.

Tabel 1. Skala Tolak Ukur WPI

\begin{tabular}{|c|c|c|c|}
\hline *Skala & *Tingkat Kemiskinan Air & **Skala & **Kondisi \\
\hline $75-85$ & Sangat rendah & \multirow[t]{2}{*}{62} & \multirow[t]{2}{*}{ Safe } \\
\hline $65-75$ & Rendah & & \\
\hline $55-65$ & Agak Rendah & $56-61,9$ & Midding safe \\
\hline $45-55$ & Sedang & $48-55,9$ & Low safe \\
\hline $35-45$ & Agak Tinggi & \multirow[t]{3}{*}{$35-47,9$} & \multirow[t]{3}{*}{ Unsafe } \\
\hline $25-35$ & Tinggi & & \\
\hline $15-25$ & Sangat tinggi & & \\
\hline
\end{tabular}

Sumber: *Shakya, 2012; **CEH Wallingford dalam Xin et al., 2011

\section{HASI L DAN DISKUSI}

- Indeks Kemiskinan Air

Hasil perhitungan indeks kemiskinan air berasal dari lima komponen dengan masing-masing nilai komponen ditunjukkan dalam diagram radar (pentagram). Berdasarkan hasil analisis, WPI di Kabupaten Bandung, Kota Bandung, dan Kota Cimahi berturutturut adalah 38,79; 42,69; dan 38,13 (Gambar 1).

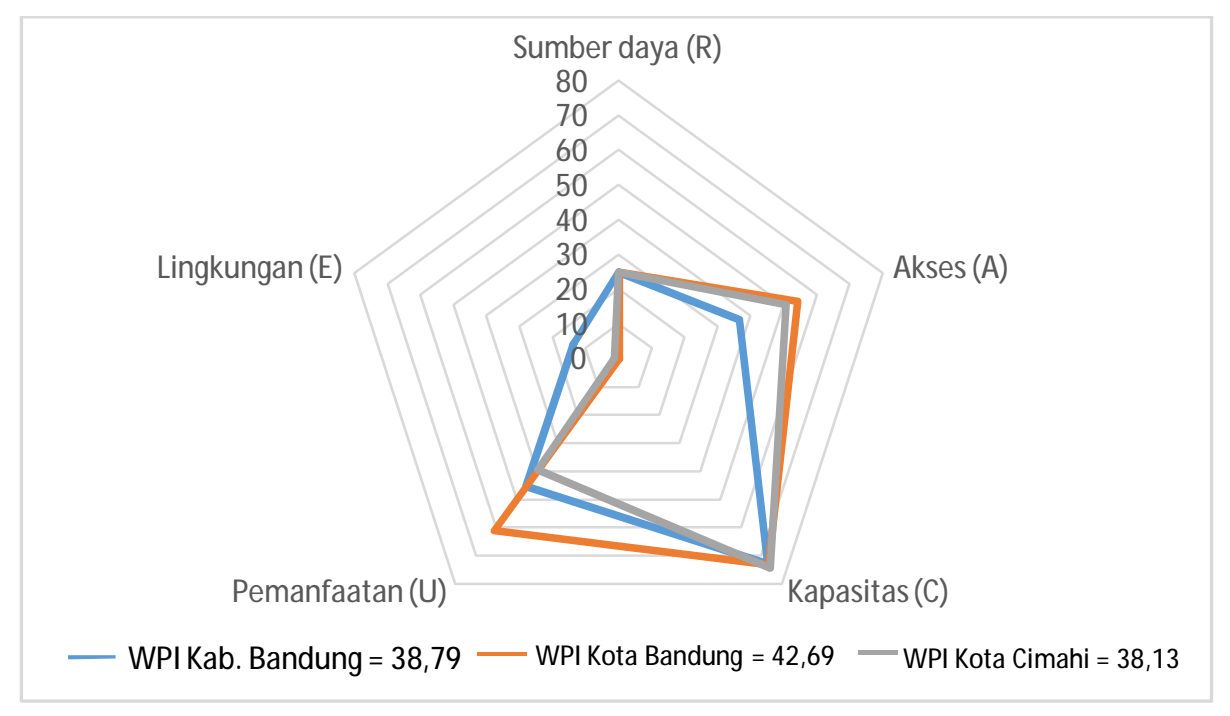

Gambar 1. Pentagram WPI

Masing-masing nilai indeks tersebut berasal dari variabel subkomponen yang ditunjukkan pada Tabel 2. Dengan menggunakan tolak ukur yang dikembangkan oleh CEH Wallingford (dalam Xin et al., 2011) dan Shakya
(2012), ketiga wilayah kajian termasuk daerah berstatus miskin air agak tinggi yang berarti bahwa ketiga wilayah tersebut berada dalam kondisi tidak aman (Tabel 3). 
Tabel 2. Nilai WPI dan Komponennya

\begin{tabular}{|l|c|c|c|c|c|c|}
\hline \multirow{2}{*}{ Wilayah } & \multicolumn{5}{|c|}{ Komponen } & \multirow{2}{*}{ WPI } \\
\cline { 2 - 6 } & $\begin{array}{c}\text { Sumberdaya } \\
(\mathrm{R})\end{array}$ & $\begin{array}{c}\text { Akses } \\
(\mathrm{A})\end{array}$ & $\begin{array}{c}\text { Kapasitas } \\
(\mathrm{C})\end{array}$ & $\begin{array}{c}\text { Pemanfaatan } \\
(\mathrm{U})\end{array}$ & $\begin{array}{c}\text { Lingkungan } \\
(\mathrm{E})\end{array}$ & \\
\hline \hline Kab. Bandung & 25 & 36,66 & 73,09 & 45,54 & 13,67 & 38,79 \\
\hline Kota Bandung & 25 & 54,05 & 73,32 & 61,05 & 0,02 & 42,69 \\
\hline Kota Cimahi & 25 & 50,62 & 74,30 & 39,48 & 1,25 & 38,13 \\
\hline
\end{tabular}

Sumber: Hasil Perhitungan

Ahmed et al. (2009) menyatakan bahwa wilayah yang mengalami perkembangan ekonomi akan berkorelasi dengan meningkatnya kebutuhan terhadap air yang kemudian menciptakan situasi kelangkaan air. Dalam beberapa tahun terakhir ini, ketiga wilayah penelitian mengalami perkembangan yang cukup pesat. Kondisi tersebut berimplikasi pada rendahnya nilai komponen untuk sumber daya. Kondisi ini bertambah buruk dengan nilai dari komponen lingkungan. Dua variabel yakni kualitas air dan tutupan vegetasi pada Komponen Lingkungan menyumbang nilai yang cukup rendah karena variabel kualitas air yang buruk tidak memberikan kontribusi nilai pada perhitungan komposit WPI.
Dalam pemenuhan kebutuhan manusia di seluruh sektor, ketiga wilayah penelitian dipandang dalam kondisi kritis sumber daya air. Menurut GinéGarriga and Pérez-Foguet (2010), permasalahan pada sumber daya air terjadi karena didorong oleh peningkatan dalam permintaan atau kebutuhan air, peningkatan sumber polusi, pengelolaan sumber daya air yang tidak memadai, kapasitas yang rendah untuk mengantisipasi dan mitigasi bencana banjir, dan akses yang rendah terhadap informasi yang berhubungan dengan suplai air. Peningkatan kebutuhan air ini mendorong terjadinya kompetisi untuk memperoleh air.

Tabel 3. Kondisi Kemiskinan Air (WPI) di Lokasi Penelitian

\begin{tabular}{|c|c|c|c|}
\hline Wilayah & WPI & Skala Kemiskinan Air & Kondisi \\
\hline \hline Kab. Bandung & 38,79 & Agak tinggi & Tidak aman \\
\hline Kota Bandung & 42,69 & Agak tinggi & Tidak aman \\
\hline Kota Cimahi & 38,13 & Agak tinggi & Tidak aman \\
\hline
\end{tabular}

Sumber: Hasil analisis (2010)

Ketiga wilayah kajian membutuhkan prioritas penanganan dalam menanggulangi kemiskinan air yang terjadi di wilayahnya masingmasing dengan memperhatikan prioritas aksi pada masing-masing sub-komponen penyebab nilai WPI yang rendah. Ketiga wilayah yakni Kabupaten Bandung, Kota Bandung, dan Kota Cimahi perlu diprioritaskan dalam komponen lingkungan dan ketersediaan Sumber Daya Air. Dalam pemenuhan akses, Kabupaten Bandung perlu meningkatkan prioritas pada air limbah domestik sehat dan sanitasi sehat, Kota Bandung pada akses air limbah sehat, dan Kota Cimahi pada akses air bersih. Dalam hal pemanfaatan air, Kota Cimahi perlu lebih memperhatikan pengurangan dalam penggunaan air industri yang tergolong tinggi. Kota Bandung dan Kabupaten Bandung pun dinilai perlu menangani pemakaian air dari sektor industri.

Strategi pengelolaan air diperlukan untuk penanggulangan kemiskinan air. Salah satunya dengan upaya konservasi air baik air permukaan maupun bawah tanah terutama dari sektor domestik, industri, dan pertanian. Bentuk konservasi air berupa penghematan penggunaan air dan 
pengelolaan limbah agar keberadaan air tidak tercemar yang kemudian dapat mengurangi ketersediaan air bersih. Peningkatan akses air bersih maupun sanitasi dan limbah perlu dilakukan secara bertahap dengan prioritas untuk penduduk yang tidak mampu. Peningkatan sumber daya manusia (SDM) dan pemberdayaan perempuan perlu terus dilakukan sebagai upaya meminimalisasi kendala nonteknis.Setiap rencana aksi pun perlu diperhatikan aspek sosial seperti budaya yang ada untuk membantu kelancaran dan kesuksesan setiap program.

\section{KESIMPULAN}

Hasil penelitian menunjukkan bahwa Kabupaten Bandung, Kota Bandung, dan Kota Cimahi memiliki Indeks Kemiskinan Air (WPI) berturutturut 38,79; 42,69; dan 38,13 dari skala 100 (paling baik). Dengan kata lain, ketiga wilayah tersebut masuk dalam kategori kemiskinan air cukup tinggi atau dalam kondisi tidak aman. Kemiskinan air di wilayah kajian terutama disebabkan oleh rendahnya nilai dari komponen lingkungan (kualitas air buruk dan sedikitnya tutupan vegetasi), ketersediaan sumber daya air yang tidak mencukupi kebutuhan penduduknya, dan akses masyarakat pada air bersih maupun sanitasi. Berdasarkan nilai WPI diperlukan pengelolaan sumber daya air dengan memprioritaskan komponen lingkungan, sumber daya, akses, dan pemanfaatan. Pengelolaan sumber daya air seperti konservasi diperlukan untuk menanggulangi kemiskinan air di wilayah-wilayah tersebut.

\section{UCAPANTERIMA KASIH}

Ucapan terima kasih disampaikan kepada Dr. Chay Asdak, Dr. Engkus Kusnadi, M.Sp., dan Ir. Totok Herwanto, M.Eng., Dr. Parikest, M.Sc., dari PSMIL UNPAD;Dr. Heru Santoso, M.App.Sc., dan rekan-rekan di Puslit Geoteknologi LIPI; Drs. Waluyo Hatmoko, M.Sc.dan rekan-rekan di PusAir Kementerian Pekerjaan Umum; Ir. Sumaji dari PSDA Jabar; Bunyamin Wiradikusumah, M.Si. Bapak Deni; Khairi Zm, S.Sos, M.E. dari Dinas Perindustrian Jabar; staf ESDM Jabar; staf Dinas Pertanian dan Tanaman
Pangan; staf Bappeda dan BPLHDJawa Barat; staf BPLH Kab. Bandung, Kota Bandung, dan Kota Cimahi; dan staf PDAM Tirta Raharja dan Tirta Wening.

\section{DAFTAR PUSTAKA}

Ahmed, A.U., J. Wang., A. Bhaskar., and W. Quabili. 2009. Water and Poverty in China's Yellow River Basin. Submitted to the Basin Focal Project CGIAR Challenge Program on Water \& Food, International Food Policy Research Institute.

Bushnaq, R.B.O. 2004. Implication of Water Management Policies on Water Poverty in Palestine. Thesis of Master of Engineering in Water and Environment, An-Najah National University, Nablus, Palestine.

Chan, N.W.W. 2012. Urban water pricing: equity and affordability. GWF Discussion Paper 1209, Global Water Forum, Canberra, Australia.

Direktorat Jenderal Cipta Karya. 2011. Penyusunan Master Plan Air Limbah Bandung Raya (Paket PPLP-K01). Laporan Konsep Laporan Akhir Tahun. Kementerian Pekerjaan Umum, Bandung.

Fenwick, C. 2010. Identifying the Water Poor: an Indicator Approach to Assessing Water Poverty in Rural Mexico. Thesis of The Department of Civil, Environmental, and Geomatic Engineering, University College London, UK.

Giné-Garriga, R. and A. Pérez-Foguet. 2010. The Enhanced Water Poverty Index: Targeting the Water Poor at Different Scales.WISA 2010 Biennial Conference.

Haryanto, E.T., T. Herwanto, dan D.R. Kendarto. 2007. erubahan Bentuk Penggunaan Lahan dan Implikasinya terhadap Koefisien Air Larian DAS Citarum Hulu Jawa Barat.Jurnal Bionatura 9(1): $1-15$.

Indriatmoko, R.H., H.D. Wahjono., S. Yudo., P.N. Rahardjo. 2004. Evaluasi Lingkungan Air Tanah di DAS Citarum Hulu. Jurnal 
Teknologi Lingkungan P3TL-BPPT 5(2): 82-94.

Kemp-Benedict, E., S. Bharwani., E. Rosa, C. Krittasudthacheewa, and N. Matin. 2010. Assessing Waterrelated Poverty Using the Sustainable Livelihoods Framework. Stockholm Environment Institute, Technical Report - 2010.

Manandhar, S., V.P. Pandey, and F. Kazama. 2011. Application of Water Poverty (WPI) in Nepalese Context: A Case Study of Kalo Gandaki River Basin (KGRB). Water Resour Manage 26: 89-107, Springer Science + Musiness Media B.V.

Mlote, S.D.M., C. Sullivan, and J. Meigh. 2002. Water Poverty Index: a Tool for Integrated Water Management. 3rd WaterNet/ Warfsa Symposium Water Demand Management for Sustainable Development', Dar es Salaam, 30-31 October 2002.

Oki, T. and S. Kanae. 2006. Global Hydrological Cycles and World Water Resources. Science 313, 1068; DOI: 10.1126/ science.1128845.

Pandey, V.P., S. Manandhar, F. Kazama. 2012. Water Poverty Situation of Medium-sized River Basins in Nepal. Water Resour Manage 26: 2475 - 2489. Springer Science + Business Media B.V.

PSDA Jabar. 2010. Masih Sekitar Cekungan Bandung. Melalui বhttp:/ / www.psda.jabarprov. go.id?=mod=detilBerita\&idMenu Kiri $=334$ \&idBerita $=16>$ [08/ 09/2012]

Setiawan, I. 2009. Strategi Pengelolaan Sumber Daya Air DAS Sumani Propinsi Sumatera Barat Pendekatan Analisis Neraca Air. Tesis Universitas Padjadjaran, Bandung.

Shakya, B. 2012. Water Poverty of Indrawati Basin, Analysis and Mapping. WWF Nepal.

Sullivan, C. 2002. Calculating a Water Poverty Index. World Development, 30(7): 1195 - 1210.
Sullivan, C.A., J.R. Meigh, A.M. Giacomello, T. Fediw, P. Lawrence, M. Samad, S. Mlote, C. Hutton, J.A. Allan, R.E. Schulze, D.J.M. Dlamini, W. Cosgrove, D.J. Priscoli, P. Gleick, I. Smout, J. Cobbing, R. Calow, C. Hunt, A. Hussain, M.C. Acreman, J. Kings, S. Malomo, E.L. Tate, D. O’Regan, S. Milner, and I. Steyl, I. 2003. The Water Poverty Index: Development and application at the community scale. Natural Resources Forum, 27: 189 - 199.

Sullivan, C.A. and J. Meigh. 2006. Application of the water poverty index at different scales: a cautionary tale. Water International, 31(3): 412-426.

United Nations Development Programme. 2006. Human Development Report: Beyond Scarcity: Power, Poverty, and the Global Water Crisis. Palgrave Macmillan. New York, USA.

Van der Vyver, C. and D.B. Jordaan. 2011. Water Poverty Mapping and its Role in Assisting Water Management. Communications of IBIMA 2011: 1-13. IBIMA Publishing, South Africa.

Wangsaatmaja, S., A. Sabar, M.A.N. Prasetiati. 2006. Permasalahan dan Strategi Pembangunan Lingkungan Berkelanjutan Studi Kasus: Cekungan Bandung. Jurnal Geologi Indonesia 1 (3): 163-171.

World Water Assessment Programme. 2009. The United Nations World Water Development Report 3: Water in a Changing World. Paris: UNESCO, and London: Earthscan.

Xin, L., W. Jun, and J. Jielin. 2011. Application of the Water Poverty Index at districts of Yellow River Basin. Advanced Materials Research, 250-253: 3469-3474.

Zhang, R., Z. Duan, M, Tan, and X. Chen. 2012. The assessment of water stress with the Water Poverty Index in the Shiyang River Basin in China. Environ Eart Sci DOI 10.1007/ s12665-012-1655-6. Springer-Verlag. 